\title{
A comparative study of multiple regression analysis and back propagation neural network approaches on plain carbon steel in submerged-arc welding
}

\author{
ABHIJIT SARKAR ${ }^{1, *}$, PRASENJIT DEY $^{1}, \mathrm{R} \mathrm{N} \mathrm{RAI}^{2}$ and SUBHAS CHANDRA SAHA ${ }^{3}$ \\ ${ }^{1}$ National Institute of Technology Agartala, Agartala, Tripura 799055, India \\ ${ }^{2}$ Production Engineering Department, National Institute of Technology Agartala, Agartala, Tripura 799046, \\ India \\ ${ }^{3}$ Mechanical Engineering Department, National Institute of Technology Agartala, Agartala, Tripura 799046, \\ India \\ e-mail: sarkarabhijit2009@gmail.com
}

MS received 10 March 2014; revised 28 August 2015; accepted 6 January 2016

\begin{abstract}
Weld bead plays an important role in determining the quality of welding particularly in high heat input processes. This research paper presents the development of multiple regression analysis (MRA) and artificial neural network (ANN) models to predict weld bead geometry and HAZ width in submerged arc welding process. Design of experiments is based on Taguchi's L16 orthogonal array by varying wire feed rate, transverse speed and stick out to develop a multiple regression model, which has been checked for adequacy and significance. Also, ANN model was accomplished with the back propagation approach in MATLAB program to predict bead geometry and HAZ width. Finally, the results of two prediction models were compared and analyzed. It is found that the error related to the prediction of bead geometry and HAZ width is smaller in ANN than MRA.
\end{abstract}

Keywords. Submerged arc welding (SAW); multi-regression analysis (MRA); artificial neural network (ANN); bead geometry and HAZ width.

\section{Introduction}

Submerged arc welding (SAW) is one of the most essential welding processes in manufacturing industries [1]. The weld bead plays an important role in determining the quality of the weld. Therefore, it is very important to set the proper welding process parameters to get the best bead geometry and HAZ width [2]. In SAW the weld quality is mainly influenced by independent variables like wire feed rate $\left(W_{\mathrm{f}}\right)$, electrode stick $\left(S_{\mathrm{o}}\right)$ out and traverse speed $\left(T_{\mathrm{s}}\right)$, and these are also represented the strength of weldment [36]. So, it is necessary to control these input parameters for quality welding. Yang et al [6] used a regression model to control the process parameters of SAW. Raveendra and Parmaris [7] applied regression analysis to predict the welding geometry. Sen et al [8] developed a mathematical model by using a multiple linear regression analysis in MINITAB 13.1 to predict the weld bead geometry for double pulse gas metal arc welding process. Rao et al [9] developed a mathematical model based on multiple regression analysis (MRA) to correlate the welding process

*For correspondence parameters and weld bead geometry and prediction of bead geometry in pulsed GMA welding.

But most of the industrial processes are non-linear, complex, and the linear mathematical models are not giving a closer approach to describe the behavior of the processes. Recently, for observing and controlling the welding processes parameters many artificial intelligence (AI) methods or technique such as fuzzy logic (FL), artificial neural networks (ANN) [10-13], artificial neural fuzzy interface system (ANFIS) [14] and expert system have been deployed as key techniques. Many researchers (Ghosh et al [15], Li et al [16]) advocating the advantages of the abovementioned models consideration of simplicity, applicability, powerful tools are reviewed. Nagesh and Datta [17] reported that artificial networks are powerful tools for analysis and modeling. An ANN model has been developed to establish the relationship between the welding process parameters and the weld bead geometry in laser welding [18], GMAW [19]. To predict and optimize the depth of penetration in hybrid $\mathrm{CO}_{2}$ laser-MIG welding, an artificial neural network was used for $5005 \mathrm{AI}-\mathrm{Mg}$ alloy [20]. Dhas and Kumanan [21] present the development of Neuro hybrid model (NHM) to predict weld bead width in SAW. 
A comparison of multiple regression analysis (MRA) with artificial neuron network (ANN) was used as methods of predicting the bead geometry and mechanical properties [22-30]. In 2014, Xiong et al [31] reported that the neural network model has a better performance than regression model for predicting the bead geometry in GMAW process. Kim et al [32] studied the back propagation neural network (BPNN) considerably more accurate than multiple regressions (MRA) in modeling bead height in metal arc welding. Moreover, the prediction with ANN is more accurate than that with a regression equation [33].

Based on above trend, the main objective of this study is to develop an MRA and ANN models and techniques for predicting the weld bead geometry and HAZ width by a SAW for a given set of welding parameters. Finally, the results by the two prediction models were compared and analyzed.

\section{Experiment design and procedure}

In the experiment, AISI 1015 mild steel plates of sizes $200 \mathrm{~mm} \times 100 \mathrm{~mm} \times 12 \mathrm{~mm}$ and $3.15 \mathrm{~mm}$ diameter mild steel electrode coated with copper were used. Table 1 shows the chemical composition of the experimental plates and electrode wire. Welding is completed by depositing bead on plate in SAW machine (ADOR WELDING LTD. INDIA, Machine No: MODEL PS-1200 (F)) as shown in figure 1. The variations of the input parameters are done as per design matrix, keeping the voltage constant. As the voltage change in the actual welding is minimum and also not controllable as per design of the power source. So, as input variables it is not included in the present study. However, its value is recorded by induction type multimeter putting on the cable. Flux used in this experiment is fused type silicon product

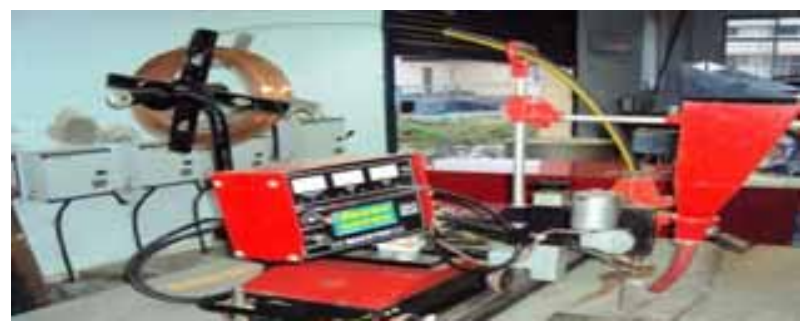

Figure 1. SAW machine [the wire feed $=50$ to $450 \mathrm{~cm} / \mathrm{min}$, welding speed $=0$ to $150 \mathrm{~cm} / \mathrm{min}$ and voltage $=415 \mathrm{~V}$ (max.)].
Table 2. Chemical composition of flux.

\begin{tabular}{lcccc}
\hline Element & $\mathrm{Al}_{2} \mathrm{O}_{3}+\mathrm{MnO}_{2}$ & $\mathrm{CaO}+\mathrm{MgO}$ & $\mathrm{SiO}_{2}+\mathrm{TiO}_{2}$ & $\mathrm{CaF}_{2}$ \\
$\mathrm{Wt} \%$ & $35 \%$ & $25 \%$ & $20 \%$ & $15 \%$ \\
\hline
\end{tabular}

with grain size $0.2-1.6 \mathrm{~mm}$ with basicity index 1.6 and the chemical composition is given in table 2 .

\section{Plan of investigation}

The present work was planned to be carried out in the following steps:

- Identifying the important process parameters and finding their limits.

- Developing the design matrix and conducting the experiments.

- Recording the response variables such as penetration $(\mathrm{P})$, bead width $(\mathrm{W})$, reinforcement $(\mathrm{R})$, and HAZ width.

- Developing mathematical models by MRA method.

- Calculating the regression co-efficient.

- Improvement of final mathematical model.

- Predicted the bead geometry shape and size by ANN model

- Comparison of MRA and ANN model.

- Analysis of results.

\subsection{Selection of process parameters and their working ranges}

Based on the effect on weld bead geometry, ease of control and capability of being maintained at the desired level, three independently controllable process parameters were identified to enable the carrying out of experimental work and developing the mathematical model. These are wire feed rate $\left(W_{\mathrm{f}}\right)$, stick out or nozzle to plate distance $\left(S_{\mathrm{o}}\right)$, traverse speed $\left(T_{\mathrm{s}}\right)$ and their upper and lower limits together with notations and units are given in table 3 .

\subsection{Developing the design matrix and conducting the experiments as per the design matrix}

In the present study, since three factors, each with four levels was selected as controllable process parameters

Table 1. Chemical composition (wt\%) of the base plate and electrode wire.

\begin{tabular}{lcccccc}
\hline Element & Carbon & Manganese & Slicon & Phosphorus & Sulphur & Carbon ${ }_{\text {equ }}$ \\
\hline Base metal & 0.163 & 0.419 & 0.150 & 0.0190 & 0.0130 & 0.240 \\
Electrode & 0.040 & 0.40 & 0.050 & - & - & - \\
\hline
\end{tabular}


Table 3. Welding process control parameters and their levels.

\begin{tabular}{lccccc}
\hline Parameters & Units & Notation & Level 1 & Level 2 & Level 3 \\
\hline Wire feed rate & $\mathrm{mm} / \mathrm{min}$ & $W_{\mathrm{f}}$ & 105 & 140 & 175 \\
Stick out & $\mathrm{mm}$ & $S_{\mathrm{o}}$ & 15 & 20 & 210 \\
Traverse speed & $\mathrm{m} / \mathrm{min}$ & $T_{\mathrm{s}}$ & 0.75 & 0.9 & 30 \\
\hline
\end{tabular}

Table 4. Design matrix with code independent process variables.

\begin{tabular}{|c|c|c|c|c|c|c|}
\hline \multirow[b]{2}{*}{ Experimental no. } & \multicolumn{3}{|c|}{ Coded variable } & \multicolumn{3}{|c|}{ Actual variable } \\
\hline & Wire feed rate $\left(W_{\mathrm{f}}\right)$ & Stick out $\left(S_{\mathrm{o}}\right)$ & Traverse speed $\left(T_{\mathrm{s}}\right)$ & Wire feed rate $\left(W_{\mathrm{f}}\right)$ & Stick out $\left(S_{\mathrm{o}}\right)$ & Traverse speed $\left(T_{\mathrm{s}}\right)$ \\
\hline 1 & 1 & 1 & 1 & 105 & 15 & 0.75 \\
\hline 2 & 1 & 2 & 2 & 105 & 20 & 0.9 \\
\hline 3 & 1 & 3 & 3 & 105 & 25 & 1.15 \\
\hline 4 & 1 & 4 & 4 & 105 & 30 & 1.2 \\
\hline 5 & 2 & 1 & 2 & 140 & 15 & 0.9 \\
\hline 6 & 2 & 2 & 1 & 140 & 20 & 0.75 \\
\hline 7 & 2 & 3 & 4 & 140 & 25 & 1.2 \\
\hline 8 & 2 & 4 & 3 & 140 & 30 & 1.15 \\
\hline 9 & 3 & 1 & 3 & 175 & 15 & 1.15 \\
\hline 10 & 3 & 2 & 4 & 175 & 20 & 1.2 \\
\hline 11 & 3 & 3 & 1 & 175 & 25 & 0.75 \\
\hline 12 & 3 & 4 & 2 & 175 & 30 & 0.9 \\
\hline 13 & 4 & 1 & 4 & 210 & 15 & 1.2 \\
\hline 14 & 4 & 2 & 3 & 210 & 20 & 1.15 \\
\hline 15 & 4 & 3 & 2 & 210 & 25 & 0.9 \\
\hline 16 & 4 & 4 & 1 & 210 & 30 & 0.75 \\
\hline
\end{tabular}

Table 5. $\mathrm{L}_{16}$ design matrix with the experiment values of bead penetration, bead width, reinforcement and HAZ width.

\begin{tabular}{|c|c|c|c|c|c|c|c|}
\hline Experimental no. & $W_{\mathrm{f}}$ & $S_{\mathrm{o}}$ & $T_{\mathrm{s}}$ & Penetration (mm) & Bead width (mm) & Reinforcement (mm) & HAZ width $(\mathrm{mm})$ \\
\hline 1 & 105 & 15 & 0.75 & 4.00 & 12.00 & 1.86 & 1.40 \\
\hline 2 & 105 & 20 & 0.90 & 3.80 & 11.20 & 1.80 & 1.37 \\
\hline 3 & 105 & 25 & 1.15 & 3.10 & 10.25 & 1.70 & 1.30 \\
\hline 4 & 105 & 30 & 1.20 & 3.20 & 10.10 & 1.50 & 1.10 \\
\hline 5 & 140 & 15 & 0.90 & 4.10 & 14.10 & 2.41 & 1.46 \\
\hline 6 & 140 & 20 & 0.75 & 4.80 & 13.26 & 2.45 & 1.82 \\
\hline 7 & 140 & 25 & 1.20 & 3.56 & 11.36 & 2.27 & 1.16 \\
\hline 8 & 140 & 30 & 1.15 & 4.00 & 10.76 & 2.37 & 1.37 \\
\hline 9 & 175 & 15 & 1.15 & 5.80 & 11.10 & 2.76 & 1.22 \\
\hline 10 & 175 & 20 & 1.20 & 5.30 & 10.00 & 2.79 & 1.24 \\
\hline 11 & 175 & 25 & 0.75 & 6.10 & 12.60 & 3.04 & 1.83 \\
\hline 12 & 175 & 30 & 0.90 & 6.26 & 11.30 & 3.50 & 1.55 \\
\hline 13 & 210 & 15 & 1.20 & 6.40 & 9.44 & 3.44 & 1.34 \\
\hline 14 & 210 & 20 & 1.15 & 7.30 & 10.00 & 3.40 & 1.30 \\
\hline 15 & 210 & 25 & 0.90 & 7.28 & 11.00 & 3.50 & 1.87 \\
\hline 16 & 210 & 30 & 0.75 & 6.52 & 11.46 & 4.45 & 1.77 \\
\hline
\end{tabular}

variables were selected for conducting the experiments. The design matrix comprises 16 experiments is used to study the entire welding parameter space when the Taguchi's $\mathrm{L}_{16}$ orthogonal array design matrix is used. Sixteen sets of test plates were welded as per the design matrix by selecting trails at random. The experimental layout for the welding process parameters using the $\mathrm{L}_{16}$ orthogonal array design matrix is shown in table 4 and table 5 . 


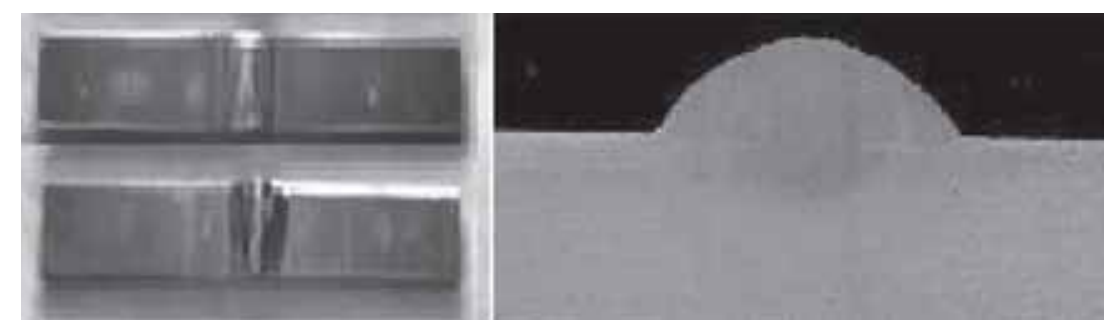

Figure 2. Image of welded samples.

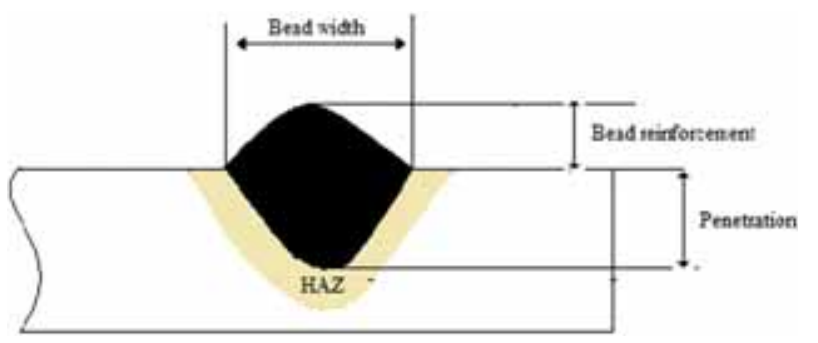

Figure 3. Weld bead geometry.

\subsection{Recording the response parameters}

Once the welding is over, all welded plates were cut approximately $100 \mathrm{~mm}$ long $\times 10 \mathrm{~mm}$ wide, transverse to the welding direction using a Buehler Abrasimet abrasive Cutter which included the bead shape and size, the heat affected zone and the base metal. After cutting, the samples were polished by different emery papers in 150, 400, 600, $1000,1200,1500$ and up to 2000 grit papers as per ASTM E3. Then prepared samples are etchant with $2 \%$ Nital solution. Then the specimens are observed through low magnification microscope attached with the micro hardness tester (Vicker's Micro hardness test machine, Model: HV-10) and the scale is used to find the dimension of various parameters of bead geometry and HAZ width. Figure 2 and figure 3 are showing the typical welded samples and weld bead geometry respectively. The average values of weld penetration $(\mathrm{P})$, width (W) and reinforcement (R) and HAZ width (from the two specimens for the same welding condition) were taken for each experiment. The dimensions of weld bead geometry of each welding condition are provided in table 5 .

\subsection{Development of mathematical models}

An MRA was carried out for better understanding of the effects of the input variables on the output variables and a linear regression equation is also deduced for the prediction of the output variables. So, a mathematical model can be developed for predicting and to establish the interrelationship between welding process parameters to weld geometry and HAZ width by MRA. The general response function representing any of the weld-bead dimensions can be expressed as

$$
\begin{gathered}
Y=f\left(W_{f}, S_{o}, T_{s}\right) \\
Y=b_{0}+b_{1} W_{f}+b_{2} S_{o}+b_{3} T_{s}
\end{gathered}
$$

where $Y$ is the depended variables or response variables such as penetration, bead width, reinforcement and HAZ width; $b_{0}, b_{1}, b_{2}$ and $b_{3}$ is the coefficient.

\subsection{Estimation of coefficients of the model}

The values of the regression coefficients of the above polynomial were calculated with the help of Minitab statistical software. The estimated regression coefficients are given in table 6 . The value of regression co-efficient gives an idea as to what extent the process parameter variables affect the response parameters. Higher values of regression co-efficient signify high influence of input variables on the response parameters and inversely relationship is found for the value of regression co-efficient which is negative.

\subsection{Testing the significance of regression coefficients}

The value of the regression coefficients gives an idea as to what extent the control variables affect the output or response variables. The less significant coefficients can be dropped along with the responses with which they are related, without sacrificing accuracy. To achieve this, $p$ value is used. According to this test when the calculated value of $p<0.05$ for the desired level of probability (say $95 \%$ ), the regression coefficient becomes significant (table 7). These conditions were satisfied for the development of final mathematical model.

\subsection{Development of final mathematical model}

The significant regression coefficients, thus selected were recalculated and final models were developed using only these coefficients. The final mathematical model is used to predict the weld bead geometry and HAZ width by substituting the above significant coefficient values in Eq. (2). This is done as per design table in coded form of the 
Table 6. Estimated regression coefficients of mathematical model for bead geometry parameters and HAZ width.

\begin{tabular}{lccrr}
\hline Coefficients & Penetration $(\mathrm{p})$ & Bead width $(\mathrm{W})$ & Reinforcement $(\mathrm{R})$ & HAZ width \\
\hline$b_{0}$ & 2.8825 & 14.2513 & 1.36375 & 1.63125 \\
$b_{1}$ & 1.1985 & -0.3408 & 0.64825 & 0.08225 \\
$b_{2}$ & -0.0725 & -0.0428 & 0.06925 & 0.03525 \\
$b_{3}$ & -0.2595 & -0.8737 & -0.17075 & -0.18775 \\
\hline
\end{tabular}

Table 7. ANOVA analysis for bead geometry and HAZ width.

\begin{tabular}{|c|c|c|c|c|c|c|}
\hline Response parameter & Source & Sum of squares & Degree of freedom & Adj. mean- squares & F-value & $p$-value \\
\hline \multirow[t]{2}{*}{$\mathrm{P}$} & Regression & 30.1800 & 6 & 10.0600 & 39.95 & 0.000 \\
\hline & Residual error & 3.02200 & 9 & 0.25200 & & \\
\hline \multirow[t]{2}{*}{ W } & Regression & 27.2060 & 6 & 3.02289 & 7.11 & 0.013 \\
\hline & Residual error & 2.54950 & 9 & 0.42491 & & \\
\hline \multirow[t]{2}{*}{$\mathrm{R}$} & Regression & 9.55748 & 6 & 1.06194 & 23.39 & 0.001 \\
\hline & Residual error & 0.27241 & 9 & 0.04540 & & \\
\hline \multirow[t]{2}{*}{ HAZ width } & Regression & 1.01480 & 6 & 0.11275 & 6.70 & 0.016 \\
\hline & Residual error & 0.10100 & 9 & 0.01683 & & \\
\hline
\end{tabular}

independent variables. Finally, based upon regression analysis the following linear equations are developed and proposed as follows:

$$
\begin{gathered}
P=2.88+1.20 W_{\mathrm{f}}-0.259 T_{\mathrm{s}} \\
W=14.8-0.964 T_{\mathrm{s}} \\
R=1.36+0.648 W_{\mathrm{f}}-0.171 T_{\mathrm{s}} \\
H A Z \text { width }=1.63+0.0822 W_{\mathrm{f}}-0.188 T_{\mathrm{s}}
\end{gathered}
$$

\section{Methodology of artificial neural network modeling}

The arrangement of neurons into layer and the connection pattern within and between the layers are called as network architecture. The architecture consists of three parts

1. Input layer receives the welding parameters

2. Hidden layer

3. Output layer obtaining the predicted values of response parameters.

The performance of the neural networks depends upon, the number of hidden layers and number of neurons in the hidden layers. It was trained to help of back propagation (BP) algorithm in MATLAB. The flow chart for the back propagation algorithm is shown in figure 4 .

In training, it is essential to balance the importance of each parameter, the data must be normalized. Since, neural networks works better in the range of 0 to 1 , the input and output vector values are converted in the range of 0 to 1 using the following equation.

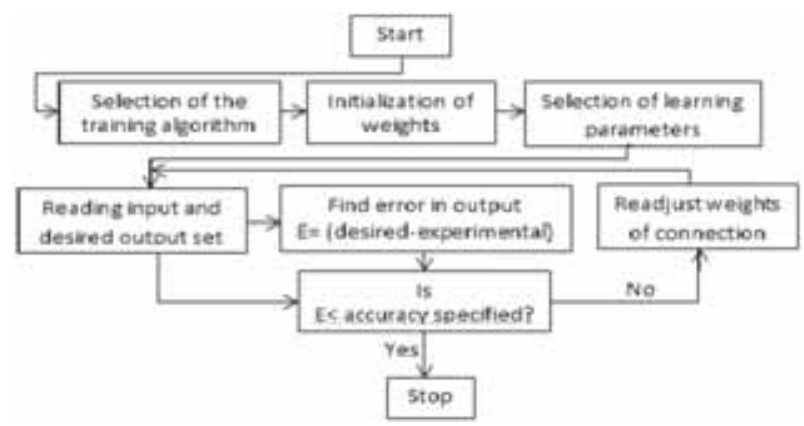

Figure 4. Flow chart for neural network.

$$
X_{n}=\left(X-X_{\min }\right) /\left(X_{\max }-X_{\min }\right)
$$

where $X_{\mathrm{n}}=$ normalized value, $X=$ actual input (or output) value, $X_{\max }=$ Maximum value of the inputs (or outputs), $X_{\min }=$ Minimum value of the inputs (or outputs)

The designed neural network structure was 3-5-4 (3 neurons in input layer, 5 neurons in hidden layer and 4 neurons in output layer). Many different ANN network algorithms have been proposed in welding process, but back propagation (BP) algorithm has been found to be the best for prediction [12]. And proposed back propagation neural network architecture is shown in figure 5.

\section{Results and discussion}

Multiple linear regression analysis is one of the most widely used methodologies for expressing the dependence of response parameters on several independent input 


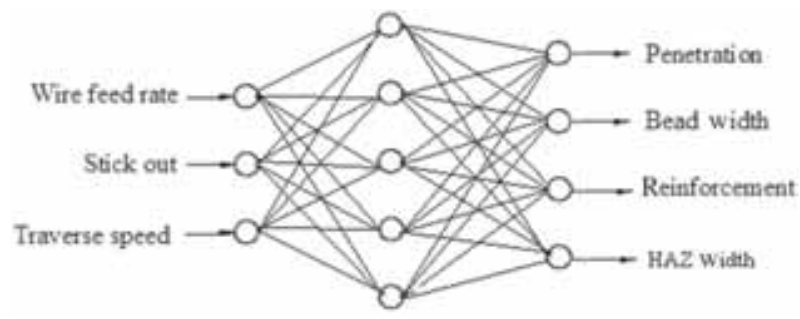

Figure 5. Back propagation neural network architecture.

Table 8. ANOVA results for mathematical model validation.

\begin{tabular}{lcc}
\hline Response parameter & R-Square (\%) & Adjusted R-square (\%) \\
\hline P & 94.40 & 86.00 \\
W & 91.43 & 78.58 \\
R & 97.23 & 93.07 \\
HAZ width & 90.95 & 77.37 \\
\hline
\end{tabular}

parameters. At first the analysis of variance (ANOVA) of the regression model is considered for the significance and also considered for finding the correlation among the variables for the better accuracy of the statistical model. The experimental data were used to develop linear models, and analysis of the models was carried out through ANOVA (table 7). Above all the final mathematical model equation is validated by $\mathrm{R}^{2}$-vlaue $(94.4 \%, 91.43 \%, 97.23 \%$ and $90.95 \%$ ) (table 8 ). The Adjusted $\mathrm{R}^{2}$-value statistic compensates for the number of variables in the model and it will only increase if added variables contribute significantly to the model. The adjusted $\mathrm{R}^{2}$-value suggests the strength of the model. The Adjusted $\mathrm{R}^{2}$-value statistic in the model for penetration, bead width, reinforcement and HAZ width are nearly $80 \%$ (table 8 ). It means that $80 \%$ of the variation in the bead geometry shape and size can be attributed to these three variables (wire feed rate, transverse speed and stick out) which ultimately suggest the good explanatory power of the regression equation.

A multi regression equation (i.e., Eqs. 3-6) was used to predict the weld bead geometry and HAZ width. The

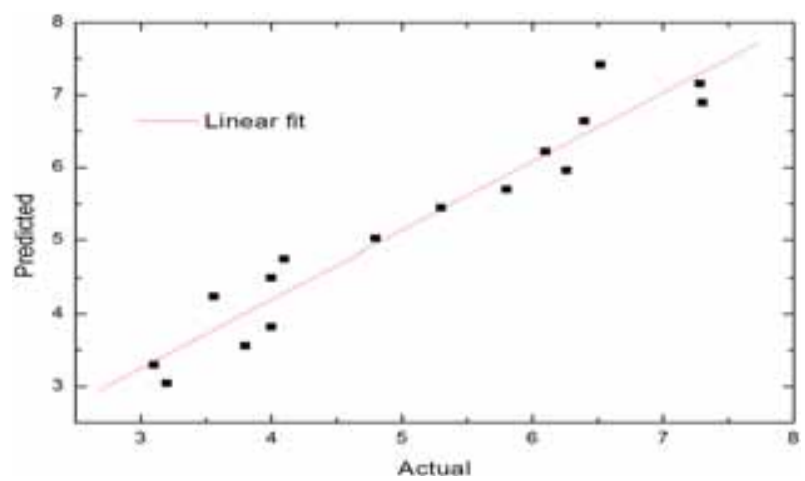

Figure 6. Scatter diagram for penetration. validity of the above equations can be judged from their coefficients of correlation and also from scatter-diagrams (figures 6, 7, 8, 9), which indicated that, a good relationship between the actual and predicted values of bead geometry and HAZ width exists. After that the value of various

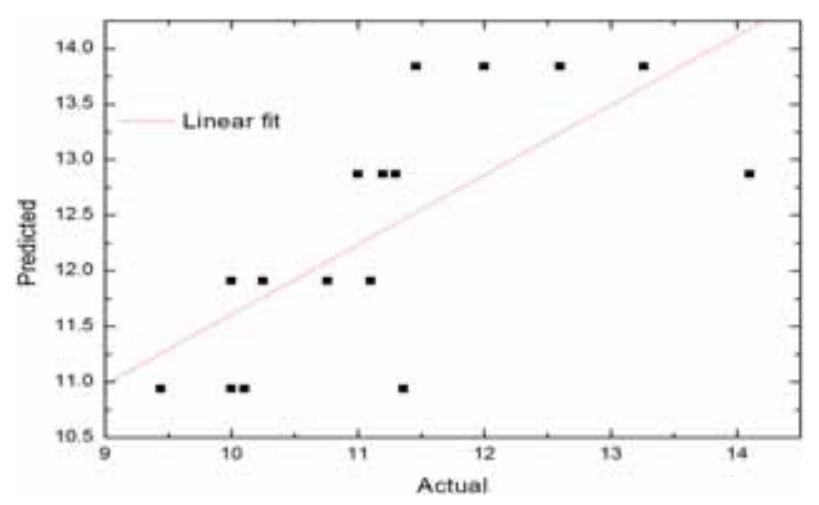

Figure 7. Scatter diagram for bead width.

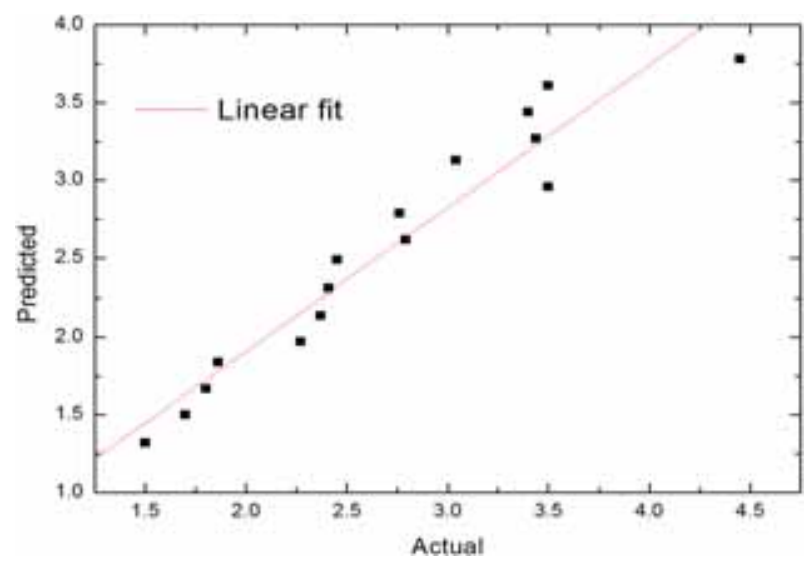

Figure 8. Scatter diagram for reinforcement.

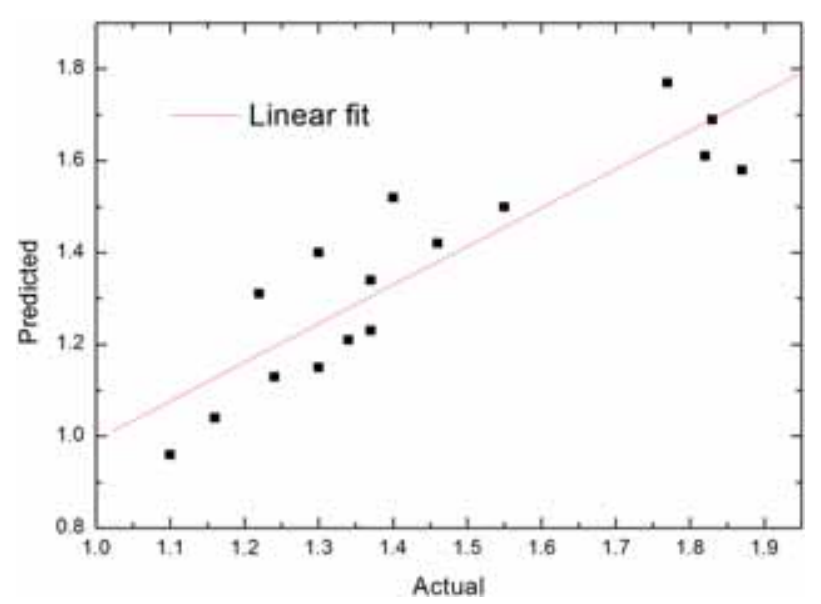

Figure 9. Scatter diagram for HAZ width. 
Table 9. Comparison of actual and predicted values of the bead geometry and HAZ width for MRA and ANN model.

\begin{tabular}{|c|c|c|c|c|c|c|c|c|c|c|c|c|}
\hline \multirow[b]{2}{*}{ S1. no } & \multirow[b]{2}{*}{$\mathrm{P}$} & \multirow[b]{2}{*}{$\mathrm{W}$} & \multirow[b]{2}{*}{$\mathrm{R}$} & \multirow[b]{2}{*}{ HAZ width } & \multicolumn{4}{|c|}{ MRA predicted value } & \multicolumn{4}{|c|}{ ANN predicted value } \\
\hline & & & & & $\mathrm{P}$ & $\mathrm{W}$ & $\mathrm{R}$ & HAZ width & $\mathrm{P}$ & $\mathrm{W}$ & $\mathrm{R}$ & HAZ width \\
\hline 1 & 4.00 & 12.00 & 1.86 & 1.40 & 3.82 & 13.84 & 1.84 & 1.52 & 3.99 & 12.00 & 1.85 & 1.39 \\
\hline 2 & 3.80 & 11.20 & 1.80 & 1.37 & 3.56 & 12.87 & 1.67 & 1.34 & 3.79 & 11.20 & 1.80 & 1.36 \\
\hline 3 & 3.10 & 10.25 & 1.70 & 1.30 & 3.30 & 11.91 & 1.50 & 1.15 & 3.14 & 10.19 & 1.71 & 1.29 \\
\hline 4 & 3.20 & 10.10 & 1.50 & 1.10 & 3.04 & 10.94 & 1.32 & 0.96 & 3.15 & 10.15 & 1.49 & 1.1 \\
\hline 5 & 4.10 & 14.10 & 2.41 & 1.46 & 4.76 & 12.87 & 2.31 & 1.42 & 3.86 & 14.09 & 2.84 & 1.46 \\
\hline 6 & 4.80 & 13.26 & 2.45 & 1.82 & 5.02 & 13.84 & 2.49 & 1.61 & 4.79 & 13.26 & 2.44 & 1.98 \\
\hline 7 & 3.56 & 11.36 & 2.27 & 1.16 & 4.24 & 10.94 & 1.97 & 1.04 & 3.55 & 11.36 & 2.25 & 1.16 \\
\hline 8 & 4.00 & 10.76 & 2.37 & 1.37 & 4.50 & 11.91 & 2.14 & 1.23 & 3.50 & 10.75 & 2.38 & 1.36 \\
\hline 9 & 5.80 & 11.10 & 2.76 & 1.22 & 5.70 & 11.91 & 2.79 & 1.31 & 5.79 & 10.50 & 2.77 & 1.22 \\
\hline 10 & 5.30 & 10.00 & 2.79 & 1.24 & 5.44 & 10.94 & 2.62 & 1.13 & 5.29 & 9.9 & 2.77 & 1.24 \\
\hline 11 & 6.10 & 12.60 & 3.04 & 1.83 & 6.22 & 13.84 & 3.13 & 1.69 & 6.10 & 12.59 & 3.04 & 1.83 \\
\hline 12 & 6.26 & 11.30 & 3.50 & 1.55 & 5.96 & 12.87 & 2.96 & 1.50 & 6.26 & 11.29 & 3.50 & 1.55 \\
\hline 13 & 6.40 & 9.44 & 3.44 & 1.34 & 6.64 & 10.94 & 3.27 & 1.21 & 6.40 & 8.44 & 3.42 & 1.33 \\
\hline 14 & 7.30 & 10.00 & 3.40 & 1.30 & 6.90 & 11.91 & 3.44 & 1.40 & 7.29 & 9.99 & 3.40 & 1.29 \\
\hline 15 & 7.28 & 11.00 & 3.50 & 1.87 & 7.16 & 12.87 & 3.61 & 1.58 & 7.28 & 11.00 & 3.50 & 1.89 \\
\hline 16 & 6.52 & 11.46 & 4.45 & 1.77 & 7.42 & 13.84 & 3.78 & 1.77 & 6.51 & 11.45 & 4.44 & 1.77 \\
\hline
\end{tabular}

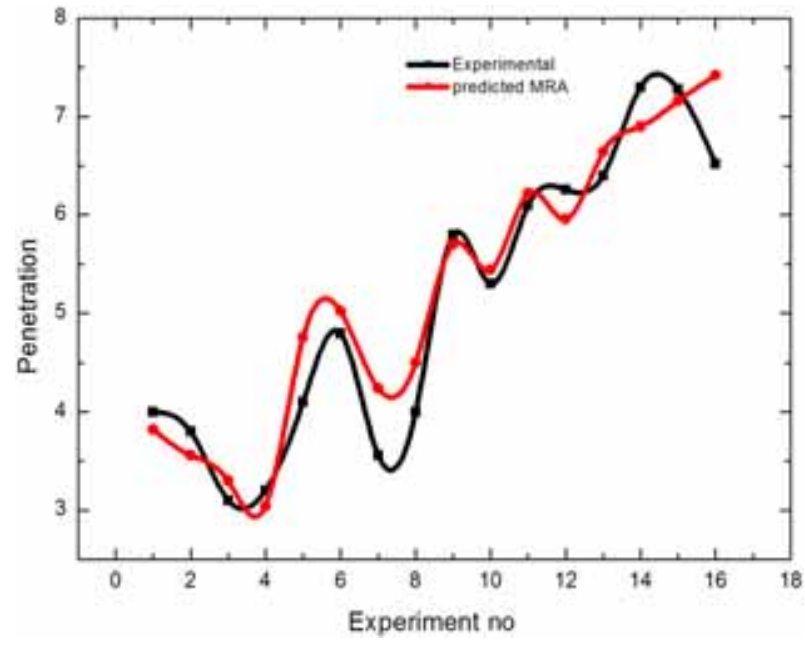

Figure 10. Actual and predicted penetration using MRA model.

parameters of bead geometry and HAZ width is calculated based upon above linear equation of the regression model and presented in table 9. The results of the experimental values and predicted values are compared and the related graphs are shown in figures 10, 11, 12 and 13. From the graphs, it is observed that the weld bead geometry and HAZ width are in good agreement except for a few combinations of parameters. Similarly the result obtained from ANN model is also provided in table 9 .

Figures 14, 15, 16 and 17 show that the relationship between the experimental and predicted values of bead geometry and HAZ width in the artificial neural network. It

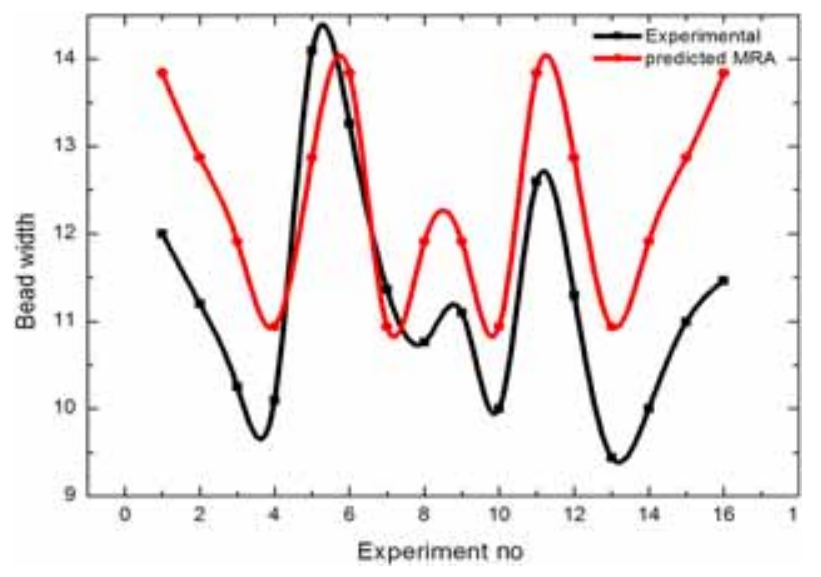

Figure 11. Actual and predicted bead width using MRA model.

can be seen from figures; the experimental and predicted values of bead geometry shape and size are too close to each other.

Further, a comparison of MRA and ANN was done to see the efficiency of a particular model. In this respect comparison graphs of predicted values of bead geometry and HAZ width are in figures 18, 19, 20 and 21. From this comparison it appears that ANN is better model comparable to MRA for predicting bead geometry and HAZ width. As the ANN model is based on non-linear concept comparable to MRA which is based on linear concept, the prediction is more accurate. However, the variation of the result based upon the above two models are within $\pm 20 \%$ (table 10). 


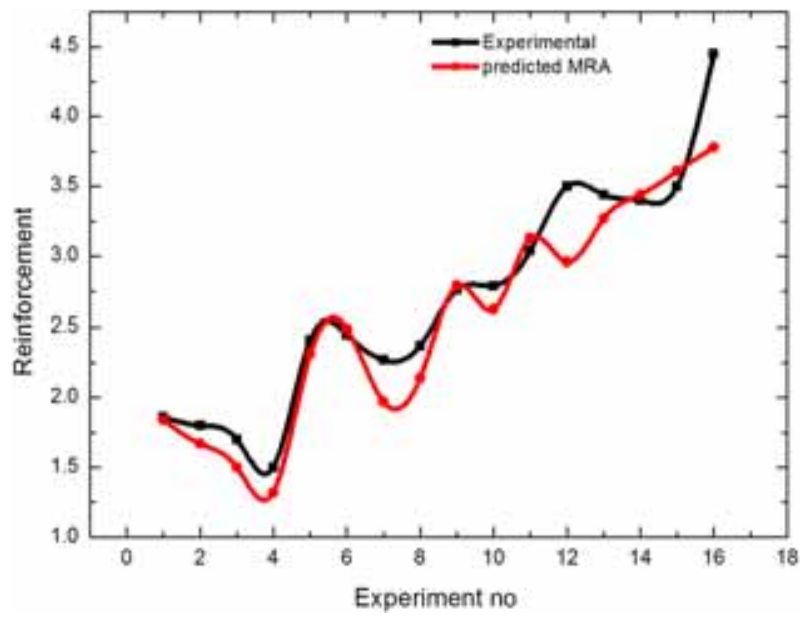

Figure 12. Actual and predicted reinforcement using MRA.

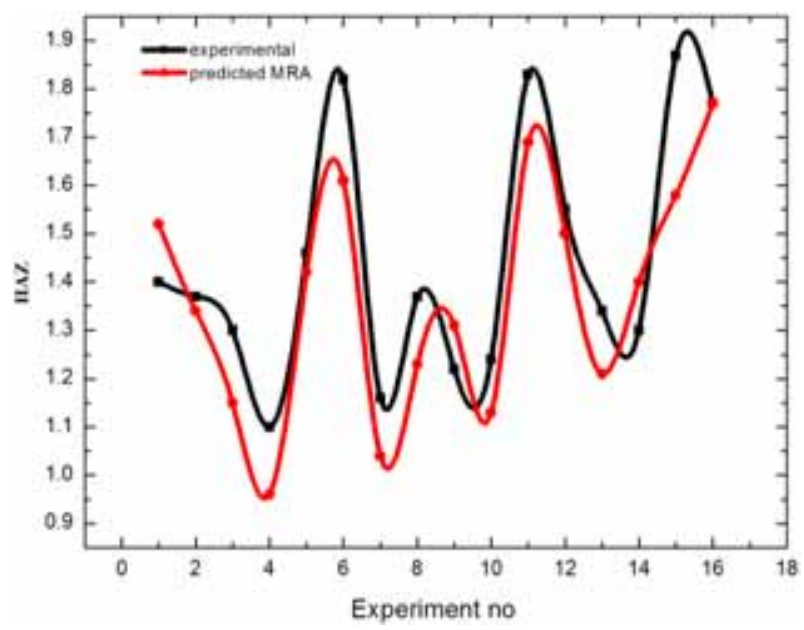

Figure 13. Actual and predicted HAZ width using MRA model.

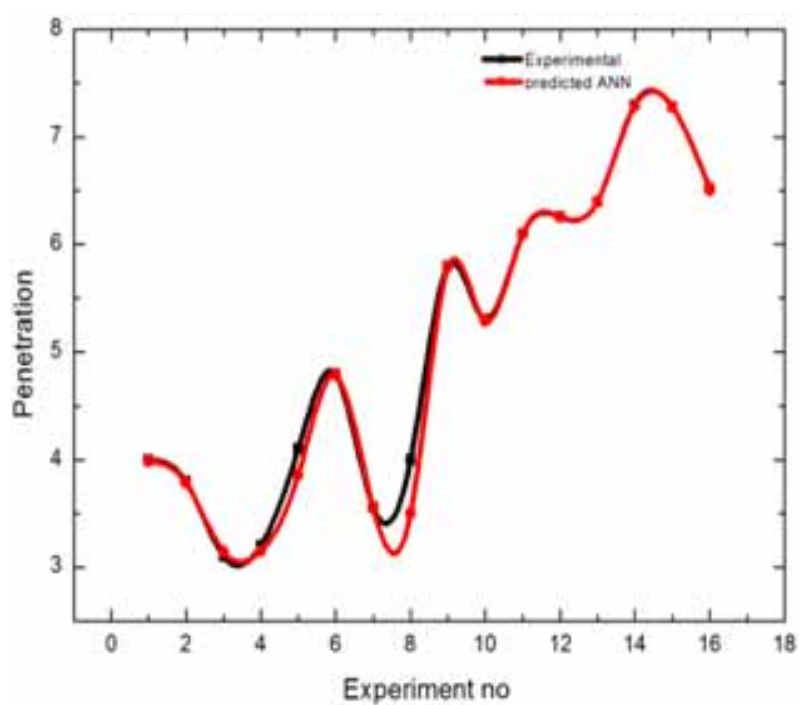

Figure 14. Actual and predicted penetration using ANN model.

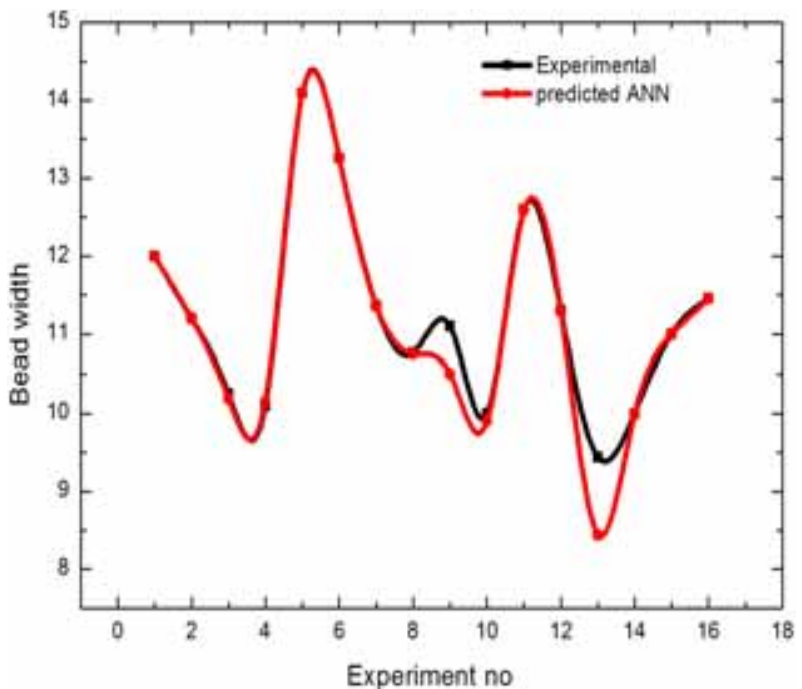

Figure 15. Actual and predicted bead width using ANN model.

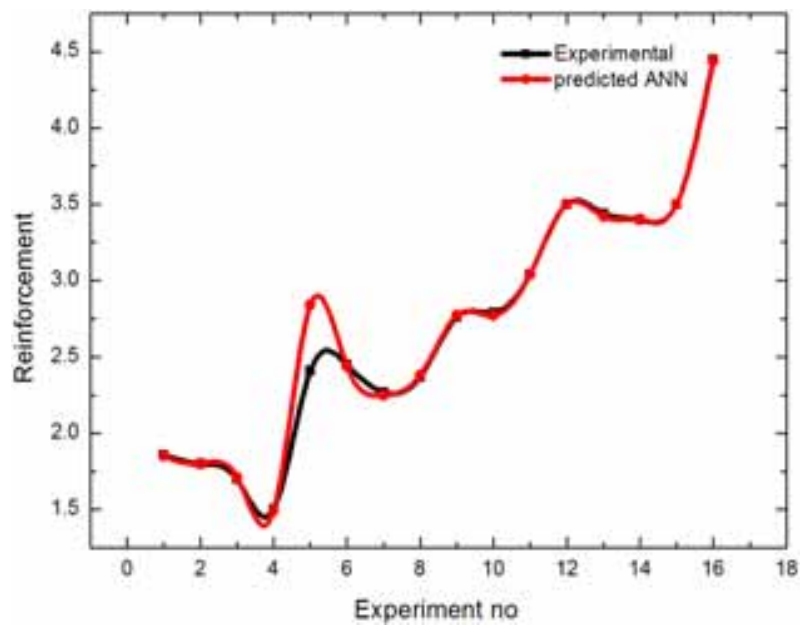

Figure 16. Actual and predicted reinforcement using ANN model.

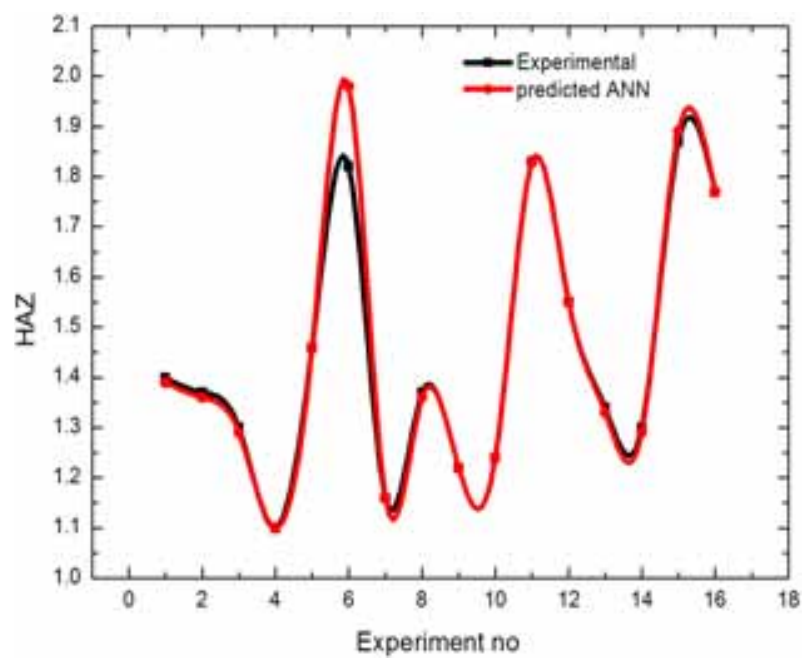

Figure 17. Actual and predicted HAZ width using ANN model. 


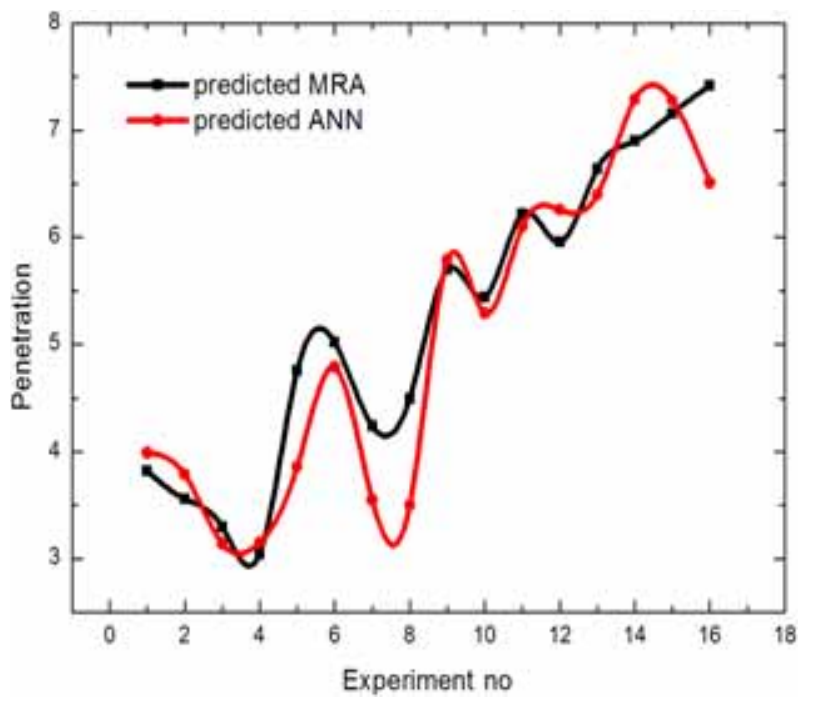

Figure 18. Predicted penetration using ANN and MRA.

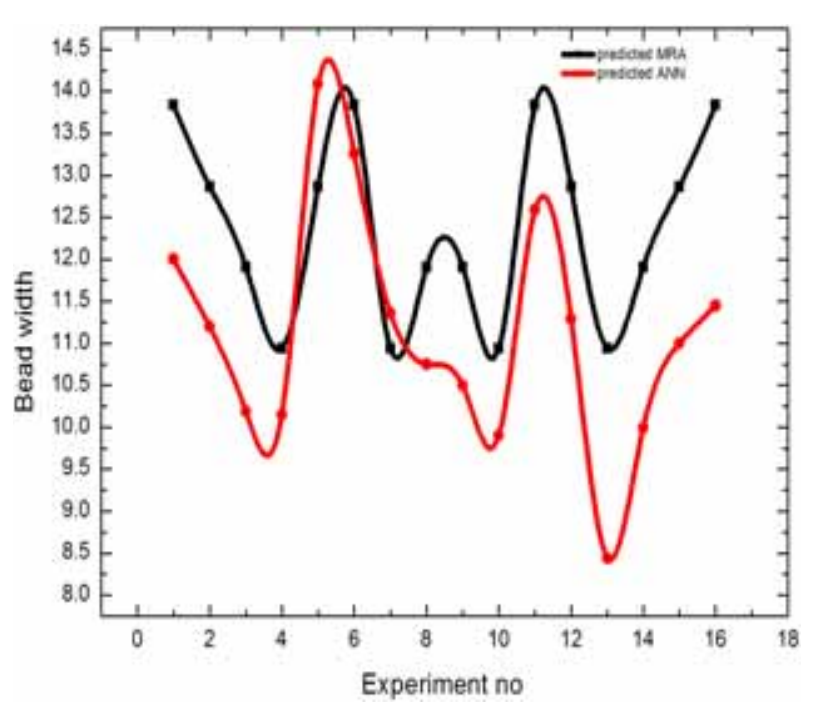

Figure 19. Predicted bead width using ANN and MRA.

\section{Conclusion}

Based on the different welding parameters ranges (wire feed rate is $105-210 \mathrm{~mm} / \mathrm{min}$; transverse speed is $0.75-1.2 \mathrm{~mm} / \mathrm{min}$; stick out is $15-25 \mathrm{~mm}$ ), the MRA and ANN are used to predict the bead geometry and HAZ width in present study and the following conclusions were drawn through comparison and analysis.

1. There is a linear relationship consequent between the welding process parameters and the weld bead geometry

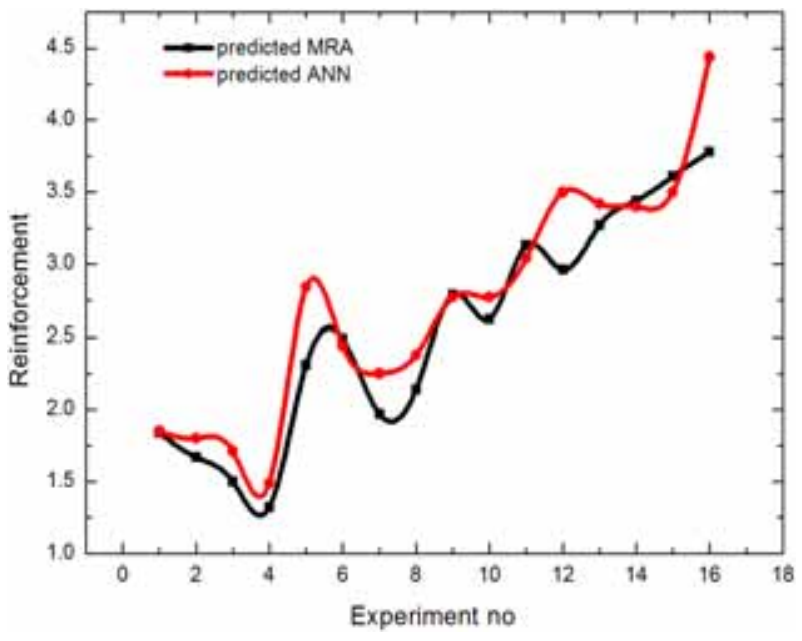

Figure 20. Predicted reinforcement using ANN and MRA.

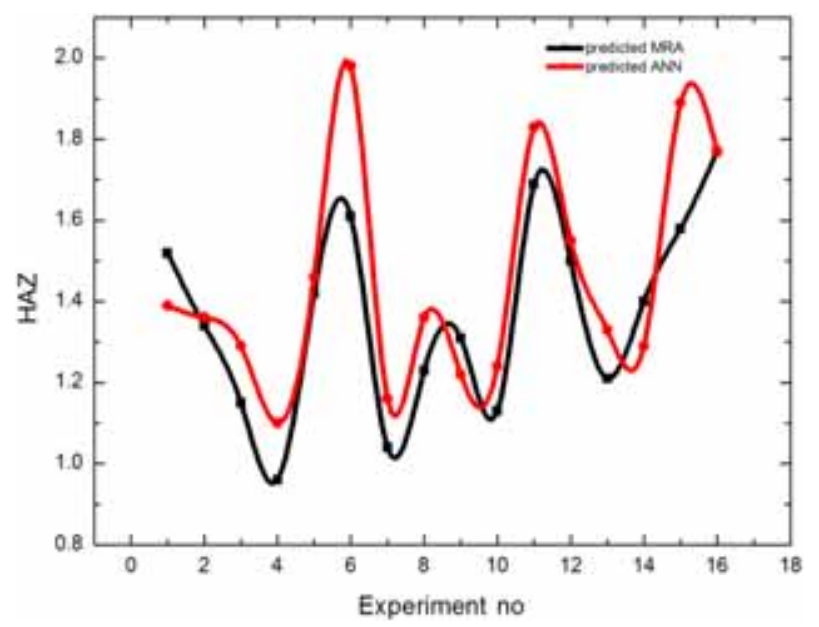

Figure 21. Predicted HAZ width using ANN and MRA.

and HAZ width in linear equations through the multiple regression analysis.

2. Developed linear equations through MRA may be used to predict the various components of weld bead geometry and HAZ width in the welding of mild steel plates by SAW process.

3. The best architecture found by using back-propagation algorithm is 3-5-4 for the present work.

4. In ANN model, the percentage errors obtained for bead geometry and HAZ width are very low. It proves that the Back Propagation ANN model developed in this study is capable of predicting weld bead geometry and HAZ width with acceptable accuracy. 
Table 10. Comparison of percentage error of predicted and actual values for MRA and ANN model.

\begin{tabular}{|c|c|c|c|c|c|c|c|c|}
\hline \multirow[b]{2}{*}{ Sl no. } & \multicolumn{4}{|c|}{$\%$ Error for MRA } & \multicolumn{4}{|c|}{$\%$ Error for ANN } \\
\hline & $\mathrm{P}$ & $\mathrm{W}$ & $\mathrm{R}$ & HAZ width & $\mathrm{P}$ & $\mathrm{W}$ & $\mathrm{R}$ & HAZ width \\
\hline 1 & 4.71 & -13.2 & 1.08 & -7.89 & 0.25 & 0.00 & 0.53 & 0.72 \\
\hline 2 & 6.74 & -12.9 & 7.78 & 2.23 & 0.26 & 0.00 & 0.00 & 0.73 \\
\hline 3 & -6.06 & -13.9 & 13.3 & 13.04 & -1.29 & 0.58 & -0.58 & 0.77 \\
\hline 4 & 5.26 & -7.67 & 13.6 & 14.5 & 1.56 & -0.49 & 0.66 & 0.00 \\
\hline 5 & -13.8 & 9.55 & 4.32 & 2.81 & 0.00 & 0.07 & 0.69 & 0.00 \\
\hline 6 & -4.38 & -4.19 & -1.60 & 13.1 & 0.20 & 0.00 & 0.41 & 0.00 \\
\hline 7 & -16.0 & 3.83 & 15.2 & 11.5 & 0.28 & 0.00 & 0.88 & 0.00 \\
\hline 8 & -11.1 & -9.65 & 10.7 & 11.3 & 0.00 & 0.09 & -0.42 & 0.73 \\
\hline 9 & 1.75 & -16.8 & -1.07 & -6.87 & 0.17 & 0.00 & -0.36 & 0.00 \\
\hline 10 & -2.57 & -8.59 & 6.48 & 9.73 & 0.18 & 1.00 & 0.72 & 0.00 \\
\hline 11 & -1.92 & -8.95 & -2.87 & 8.28 & 0.00 & 0.07 & 0.00 & 0.00 \\
\hline 12 & 5.03 & -12.1 & 18.2 & 3.34 & 0.00 & 0.08 & 0.00 & 0.00 \\
\hline 13 & -3.61 & -13.7 & 5.19 & 10.7 & 0.00 & 0.00 & 0.58 & 0.75 \\
\hline 14 & 5.79 & -16.0 & -1.16 & -7.14 & 0.13 & 0.11 & 0.00 & 0.77 \\
\hline 15 & 1.67 & -14.5 & -3.04 & 18.3 & 0.00 & 0.00 & 0.00 & 0.53 \\
\hline 16 & -12.1 & -17.1 & 17.7 & 0.00 & 0.15 & 0.08 & 0.23 & 0.00 \\
\hline
\end{tabular}

5. The prediction accuracy is better in ANN than MRA model and the variation of the result based upon the two models are within $\pm 20 \%$.

\section{References}

[1] Weimann D H 1991 A study of welding procedure generation for submerged-arc welding process. Queen's University of Belfast

[2] Chandel R, Seow H and Cheong F 1997 Effect of increasing deposition rate on the bead geometry of submerged arc welds. J. Mater. Process. Technol. 72(1): 124-128

[3] Apps R L, Gourd L M, Lelson K A 1963 Effect of welding variables upon bead shape and size in SAW. Weld Metal Fabrication 31: 453-457

[4] Kiran D, Basu B and De A 2012 Influence of process variables on weld bead quality in two wire tandem submerged arc welding of HSLA steel. J. Mater. Process. Technol. 212(10): 2041-2050

[5] Lee C, Chandel R and Seow H 2000 Effect of welding parameters on the size of heat affected zone of submerged arc welding. Mater. Manuf. Process. 15(5): 649-666

[6] Yang L,. Bibby M and Chandel R 1993 Linear regression equations for modeling the submerged-arc welding process. J. Mater. Process. Technol. 39(1): 33-42

[7] Raveendra J and Parmaris R 1987 Mathematical models to predict weld bead geometry for flux cored arc welding. Metal Constr. 19(1): 31

[8] Sen M, Mukherjee M, and Pal T K 2014 Prediction of weld bead geometry for double pulse gas metal arc welding process by regression analysis. Fifth International and 26th All India Manufacturing Technology, Design and Research Conference, 814-6, IIT Guwahati, Guwahat

[9] Rao P S, Gupta O, Murty S and Rao A K 2009 Effect of process parameters and mathematical model for the prediction of bead geometry in pulsed GMA welding. Int. J. Adv. Manuf. Technol. 45(5-6): 496-505

[10] Andersen K, Cook G E, Karsai G and Ramaswamy K 1990 Artificial neural networks applied to arc welding process modeling and control. IEEE Trans. Ind. Appl. 26(5): 824-830

[11] Chokkalingham S, Chandrasekhar N and Vasudevan M 2012 Predicting the depth of penetration and weld bead width from the infra red thermal image of the weld pool using artificial neural network modeling. J. Intell. Manuf. 23(5): 1995-2001

[12] Kanti K M and Rao P S 2008 Prediction of bead geometry in pulsed GMA welding using back propagation neural network. J. Mater. Process. Technol. 200(1): 300-305

[13] Nagesh D and Datta G 2010 Genetic algorithm for optimization of welding variables for height to width ratio and application of ANN for prediction of bead geometry for TIG welding process. Appl. Soft Comput. 10(3): 897-907

[14] Akkas N, Karayel D, Ozkan S S, Oğur A and Topal B 2013 Modeling and analysis of the weld bead geometry in submerged arc welding by using adaptive neurofuzzy inference system. Math. Problems Eng. doi: 10.1155/2013/473495

[15] Ghosh A, Mukherjee S, Chattopadhyaya S and Sarkar P 2007 Weldbead parametric estimation of SAW process through neural network. Ind. Welding J. 40(4): 33

[16] Li P, Fang M T C and Lucas J 1997 Modelling of submerged arc weld beads using self-adaptive offset neutral networks. $J$. Mater. Process Technol. 71(2): 288-298

[17] Nagesh D and Datta G 2002 Prediction of weld bead geometry and penetration in shielded metal-arc welding using artificial neural networks. J. Mater. Process. Technol. 123(2): 303-312

[18] Sathiya P, Panneerselvam K and Jaleel M A 2012 Optimization of laser welding process parameters for super austenitic stainless steel using artificial neural networks and genetic algorithm. Mater. Des. 36: 490-498

[19] Campbell S, Galloway A and McPherson N 2012 Artificial neural network prediction of weld geometry performed using GMAW with alternating shielding gases. Welding J. 91(6): 174-181 
[20] Ghosal S and Chaki S 2010 Estimation and optimization of depth of penetration in hybrid $\mathrm{CO}_{2}$ LASER-MIG welding using ANN-optimization hybrid model. Int. J. Adv. Manuf. Technol. 47(9-12): 1149-1157

[21] Dhas J E R and Kumanan S 2010 Neuro hybrid model to predict weld bead width in submerged arc welding process. $J$. Scientific Ind. Res. 69: 350-355

[22] Acherjee B, Mondal S, Tudu B and Misra D 2011 Application of artificial neural network for predicting weld quality in laser transmission welding of thermoplastics. Appl. Soft Comput. 11(2): 2548-2555

[23] Balasubramanian K, Buvanashekaran G and Sankaranarayanasamy K 2007 Mathematical and ANN modeling of Nd: YAG laser welding of thin SS sheets. J. Manuf. Eng. 6(2): 56-60

[24] Huang W and Kovacevic R 2011 A neural network and multiple regression method for the characterization of the depth of weld penetration in laser welding based on acoustic signatures. J. Intell. Manuf. 22(2): 131-143

[25] Jeong S and Cho H 1997 An analytical solution to predict the transient temperature distribution in fillet arc welds. Welding J. -Including Welding Res. Suppl. 76(6): 223s

[26] Juang S, Tarng Y and Lii H 1998 A comparison between the back-propagation and counter-propagation networks in the modeling of the TIG welding process. J. Mater. Process. Technol. 75(1): 54-62

[27] Lee J and Um K 2000 A comparison in a back-bead prediction of gas metal arc welding using multiple regression analysis and artificial neural network. Opt. Lasers Eng. 34(3): $149-158$

[28] Pal S, Pal S K and Samantaray A K 2008 Artificial neural network modeling of weld joint strength prediction of a pulsed metal inert gas welding process using arc signals. $J$. Mater. Process. Technol. 202(1): 464-474

[29] Prajapati R B, Patel D K, Patel M I and Bilash Pandey S 2014 Artificial neural network modeling of weld joint strength of gas metal arc welding process. Int. J. Adv. Sci. Tech. Res. 3(4): 769-777

[30] Towsyfyan H, Gholamreza D, Heidarian D B and Kariminasab A 2013 Comparing the regression analysis and artificial neural network in modeling the SAW (SAW) process. Res. J. Appl. Sci. Eng. Technol. 5(9): 2701-2706

[31] Xiong J, Zhang G, Hu J and Wu L 2014 Bead geometry prediction for robotic GMAW-based rapid manufacturing through a neural network and a second-order regression analysis. J. Intell. Manuf. 25(1): 157-163

[32] Kim I-S, Lee S-H and Yarlagadda P K 2003 Comparison of multiple regression and back propagation neural network approaches in modelling top bead height of multipass gas metal arc welds. Sci. Technol. Welding Join. 8(5): 347-352

[33] Shen X, Huang W, Xu C and Wang X 2009 Bi-directional prediction between weld penetration and processing parameters in electron beam welding using artificial neural networks. Advances in Neural Networks-ISNN 2009, Springer: 1097-1105 